OPEN ACCESS

Edited by:

Sajjad Ahmad,

University of Nevada, Las Vegas,

United States

Reviewed by:

Mostafa Yuness Abdelfatah Mostafa,

Minia University, Egypt

Edward Boone,

Virginia Commonwealth University, United States

*Correspondence:

Aaron Williams

WilliaA@RJRT.com

Specialty section:

This article was submitted to Environmental health and Exposome,

a section of the journal

Frontiers in Public Health

Received: 14 May 2021 Accepted: 12 October 2021 Published: 16 November 2021

Citation:

Camacho OM, Hill A, Fiebelkorn S,

Williams A and Murphy J (2021) Investigating the Health Effects of 3 Coexisting Tobacco-Related Products

Using System Dynamics Population Modeling: An Italian Population Case Study. Front. Public Health 9:700473.

doi: 10.3389/fpubh.2021.700473

\section{Investigating the Health Effects of 3 Coexisting Tobacco-Related Products Using System Dynamics Population Modeling: An Italian Population Case Study}

\author{
Oscar M. Camacho ${ }^{1}$, Andrew Hill ${ }^{2}$, Stacy Fiebelkorn ${ }^{1}$, Aaron Williams ${ }^{1 *}$ and \\ James Murphy ${ }^{1}$
}

${ }^{1}$ British American Tobacco, R\&D, Southampton, United Kingdom, ${ }^{2}$ Ventana Systems UK Ltd., Salisbury, United Kingdom

With the proliferation of tobacco products, there might be a need for more complex models than current two-product models. We have developed a three-product model able to represent interactions between three products in the marketplace. We also investigate if using several implementations of two-product models could provide sufficient information to assess 3 coexisting products. Italy is used as case-study with THPs and e-cigarettes as the products under investigation. We use transitions rates estimated for THPs in Japan and e-cigarettes in the USA to project what could happen if the Italian population were to behave as the Japanese for THP or USA for e-cigarettes. Results suggest that three-product models may be hindered by data availability while two product models could miss potential synergies between products. Both, THP and E-Cigarette scenarios, led to reduction in life-years lost although the Japanese THP scenario reductions were 3 times larger than the USA e-cigarette projections.

Keywords: tobacco, nicotine, e-cigarettes, tobacco heating products, population modeling

\section{INTRODUCTION}

The concept of tobacco harm reduction was outlined by the Institute of Medicine (IOM) in 2001, in their monolog called Clearing the Smoke (1). They suggested a strategy for harm reduction based on the replacement of risky tobacco products like cigarettes with lower risk products. Products with potential for harm reduction were defined as products able to reduce users' exposure to one or more tobacco toxicants with these exposure reductions having a disease relevant impact.

Since then, numerous tobacco products have been developed around the World which have been suggested as potential reduced risk products (PRRP) and have been assessed for their role in the smoking harm reduction paradigm. It was the U.S. Food and Drug Administration (FDA) who first suggested in their Modified Risk Tobacco Products (MRTP) application guidance (2) to use mathematical models, as part of a weight of evidence approach, to evaluate the potential health effects from launching new tobacco products in the USA. A diverse range of models have been developed for this purpose, many of them founded by the tobacco product manufacturers as part of their submission strategies, but this topic has also attracted academic attention (3). All these models investigate the effect of launching a new tobacco product with respect to a scenario where only cigarettes are available (4-6). However, given the success of product categories such as 
e-cigarettes or tobacco heated products (THP) in markets around the world, a two-product model may not be sufficient to appropriately represent tobacco use dynamics. For example, in a market with already a PRRP and smoking, introducing a new tobacco product with a risk higher than the already marketed PRRP could lead to population harm if it appeals to the users of the marketed PRRP rather than smokers. In this paper we consider whether a three-product model would be necessary in that situation or whether evaluation of two independent twoproduct models could be a satisfactory approach to investigate the potential health effects from launching a product which could perturb the dynamics affecting PRRPs already in the marketplace.

Briefly, THPs are an emerging category of tobacco products in many markets and they have proved highly successful in Asian markets like Japan and South Korea (7). THPs have been shown to produce fewer toxicants than conventional cigarettes because the tobacco is heated without combustion, leading to reduced exposure to toxicants in clinical studies and therefore, they are expected to have a lower-risk profile than cigarettes (8-10). Ecigarettes are even more widespread than THPs, in 2018 in the USA, 3.2\% of all adults reported to be current users and $14.9 \%$ ever users (11). Commonly, e-cigarettes do not contain tobacco and are comprised of a battery connected to a heating element and an e-liquid container. Although there are a wide range of products within this category, in general, the aerosol formed by e-cigarettes has been reported to be simpler and with lower level of toxicants than cigarette smoke and people using e-cigarettes exclusively are exposed to lower level of toxicants than smokers $(12,13)$.

There are currently few markets where e-cigarettes and THPs coexist, but Italy was one of the first markets to experience this with THPs launched in 2014 and vaping products already available for nearly a decade (14), but still, very little is known about the potential population effects of these products in Italy (15). In 2012, manufactured cigarettes were the dominant product, accounting for $94.6 \%$ of consumption (16). Two years later, $0.4 \%$ of people aged $15+$ were regular e-cigarette users. This increased to $1.8 \%$ in 2016 and then declined to $1.3 \%$ in 2018. THP products have also increased in market share with reports suggesting an increase from $0.01 \%$ in 2015 to $0.67 \%$ in 2017 and is expected to continue growing (17). There is no information about transitions between different products, but Italy has excellent smoking and demographic data easily accessible from Italian public sources which makes it a good candidate for modeling purposes.

Based on a previous two-product model (18), we have developed a three-product model able to assess interaction between three products. We describe its complexity and the vast amount of data required to inform such a model. Then, using our two-product model, we assess whether two independent

Abbreviations: BAT, British American Tobacco; BMJ, British Medical Journal; COT, Committee of Toxicology; ENDS, Electronic Nicotine Devices; FDA, U.S. Food and Drug Administration; ISTAT, Italian National Institute of Statistics; MAE, Mean Absolute Error; MAEoM, Mean Absolute Error Over Mean; PHE, Public Health England; PRRP, Potential Reduced Risk Product; THP, Tobacco Heated Product; US DHHS, U.S. Department of Health and Human Services. implementations of a two-product model could be used to investigate potential health outcomes and hence avoid the complexity of a three-product model. To illustrate the different modeling approaches we use e-cigarettes and THPs as the two coexisting PRRPs and Italy as the population of interest.

\section{METHODS}

\section{Product Use Definitions}

All the product modes distinguish the population by their smoking characteristics. The basis for defining a person by their smoking characteristics in this study was determined by the data source used for smoking prevalence, in this case the ISTAT reporting of the "Multipurpose survey on households: aspects of daily life." The survey definition of a Current Smoker was someone who answered yes to the question "did they currently smoke?" The definition of a Former Smoker is someone that replied no to the same question, but in a follow up question responded that "they used to smoke in the past." A Never Smoker is anyone that does not fall into either of those two categories and an Ever Smoker is the combined grouping of Current and Former Smokers.

\section{Models Description}

Our System Dynamics population models have been ensembled sequentially from simpler models to represent either one, two or three tobacco products in a marketplace.

All models are run from 2001 to 2100 , using a time step of 1 year.

Prior to the introduction of new tobacco products to the marketplace, the one product stock and flow model of a population characterized by their cigarette smoking behavior is shown in Figure 1.

All the stocks and flows are further categorized by gender and single year age cohorts. The Former Smoker stock is further broken down by the number of years abstinent from smoking up to 20 years and then a combined grouping of $20+$ years.

The model tracks population sizes by gender and single year ages $(0-100)$. At each time step, populations are aged by 1 year less any mortality rate at that age. The mortality rate for those aged 100 is set to be $100 \%$.

The introduction of a single PRRP such as e-cigarettes to the marketplace requires an expanded two-product model. The model's complexity increases reflecting the incorporation of the smoking status groups created with the number of tobacco characterized stocks increasing from 3 to 9 and potential product use transitions to 27 (Figure 2). In a one product model there is only one potential product transition flow from each population stock (initiate, quit or relapse), in the two-product model there are three potential transition outflows from each population stock.

Based on previous models it is easy to see how a three-product model expands the model structural complexity further still. In a market where there are two PRRPs available, the three-product model expands the number of stocks of population tobacco product usage further to 27 each with 7 potential product use transitions from each, a total of 189 potential transition flows. 


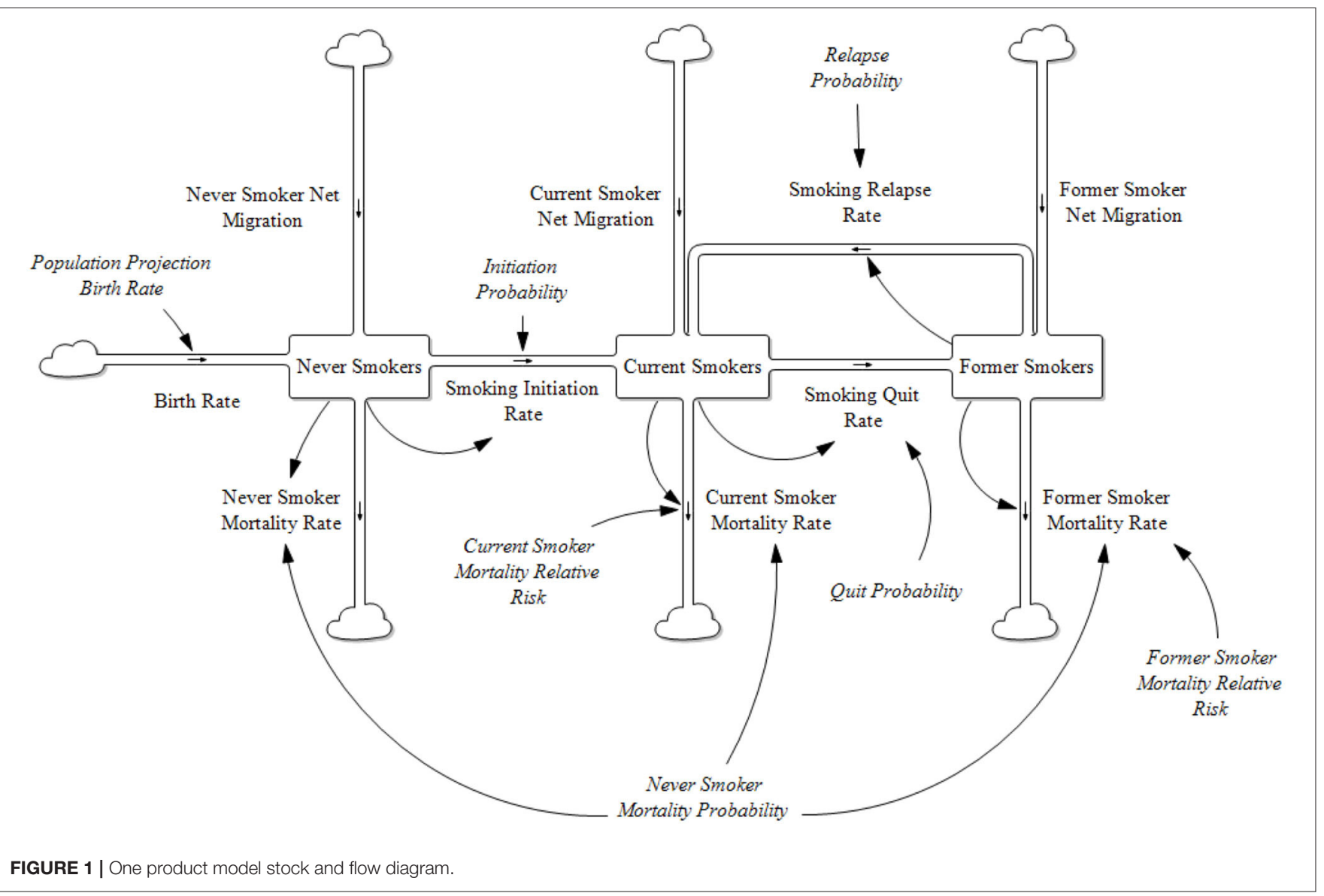

The models were developed in Vensim DSS ${ }^{\circledR}$ software. The number of variables by type for the two and three product models are shown in Table $\mathbf{1 .}$

With subscripting included, the two-product model has 48 thousand equations calculated at each time step, the threeproduct model has 104 thousand.

As data regarding transitions for e-cigarettes, THPs and interactions between the three-products were not available, in its place best "guess" estimates based on smoking have been used. Details about the data inputs and multiple assumptions required to inform the three-product model can be found in Supplementary File 1. For the two-product model implementations, in order to provide more useful projections than modelers' best estimates, we used published transition data between smoking and e-cigarettes estimated for the USA population (19) and transitions between THP and smoking estimated for the Japanese population (20). In the E-Cigarette scenarios, e-cigarettes are considered to be in the Italian market from 2010 while THP products are introduced in scenarios from 2014. More details about the data inputs for the two-product models can be found in Table 2 while, a description of the two-product model formulation and data initialization is contained in Supplementary File 2. Model calibration and verification is provided in Supplementary File 3. A detailed map of the transitions and the transition rates used is provided in Supplementary File 4.

\section{ANALYSES}

Scenarios for our three-product model are built to illustrate data requirements and outputs.

\section{Three-Product Model Scenarios}

Two main scenarios were produced for illustrative purpose only displaying comparisons in terms of life-years lost cumulatively up to the year 2100. The scenarios were:

1. Baseline scenario in which neither e-cigarettes or THPs have ever existed.

2. Scenario representing current Italian market with only ecigarettes and smoking.

3. Scenario representing current Italian market with both ecigarettes and THP products. This scenario itself was assessed under 6 different conditions. Scenario 3.1 considered that initiation of e-cigarettes and THP use are mutually exclusive or initiation between those groups are not competitive. Then we also assessed what would be the life-years projections if different percentages (20-100\%) of e-cigarette users (lowest risk product) were to instead initiate THP use. 


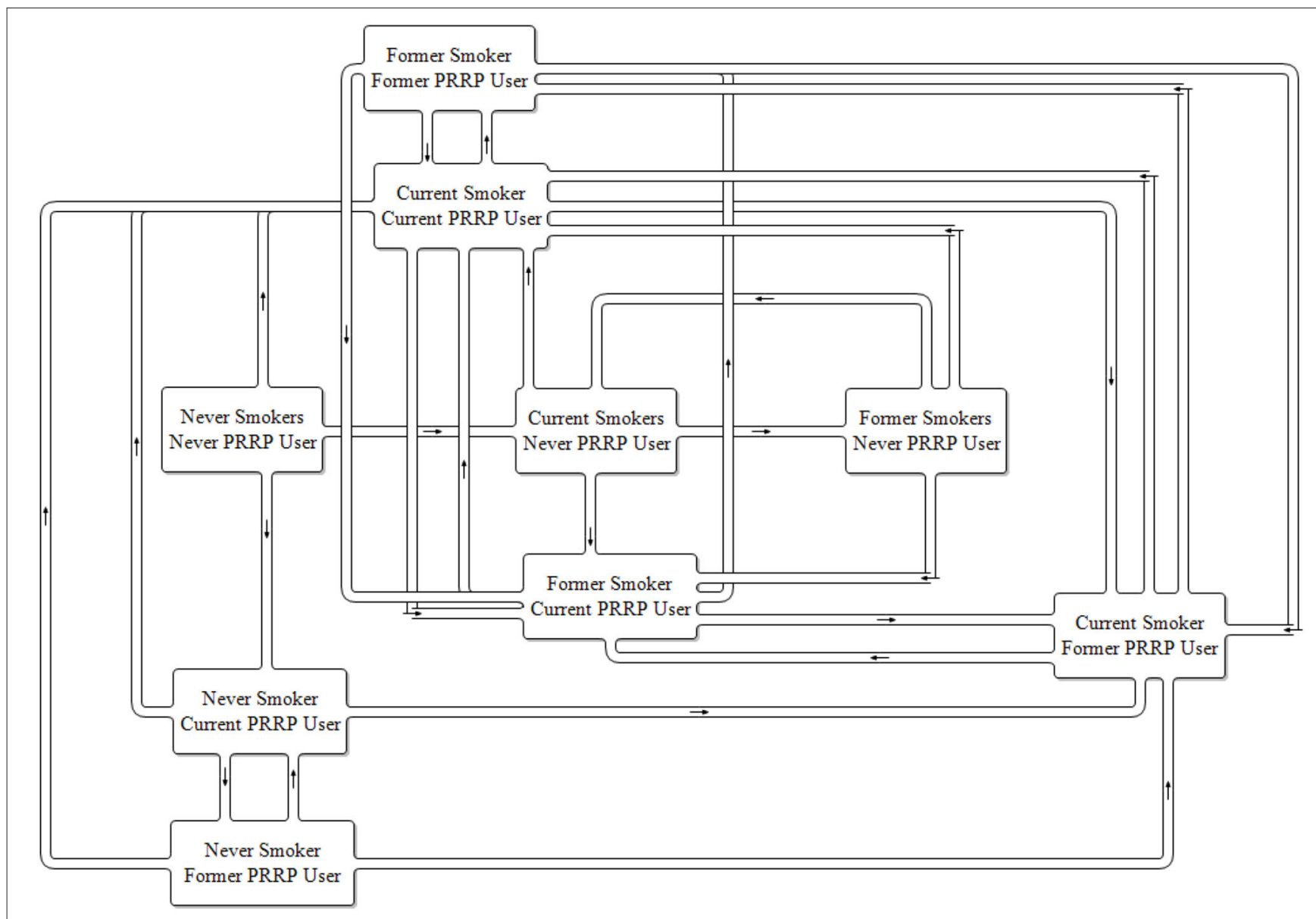

FIGURE 2 | Two product model stock and flow diagram. PRRP, Potentially Reduced Risk Product.

TABLE 1 | Model type variables.

\begin{tabular}{|c|c|c|c|c|c|c|c|c|}
\hline Model & Levels & Initial & Constant & Data & Flow & Aux & Lookup & Subscripts \\
\hline 2 Product & 34 & 45 & 61 & 4 & 15 & 300 & 4 & 28 \\
\hline 3 Product & 151 & 296 & 67 & 3 & 66 & 1,169 & 0 & 128 \\
\hline
\end{tabular}

\section{Two-Product Model Scenarios}

The projection scenarios assessed are described below. Information within brackets denotes whether the scenario was modeled using mean estimates of transition probability (deterministic) or from random sampling the estimate from with 95\% confidence interval ranges (sensitivity).

\section{Scenario Descriptions}

\section{Smoking Only (Deterministic)}

The model includes cigarettes as the only tobacco product available.

2. Smoking and E-Cigarettes (Deterministic)

E-cigarettes are added as the only alternative product to cigarettes in 2010.

\section{Smoking and THP (Deterministic)}

THPs are added as the only alternative product to cigarettes in 2014.

4. Combined E-Cigarette and THPs at a Ratio of 50:50 (Deterministic)

A single pseudo PRRP is generated by combining e-cigarette \& THP transition rates at $50 \%$ of each. In addition, the risk ratio of the pseudo PRRP is set to the midpoint between the e-cigarette and THP risk ratio, $7.5 \%$ that of combustible cigarettes.

5. Combined E-Cigarette and THPs at a Ratio of 63:37 (Deterministic)

E-cigarette \& THP transition rates are combined at $63 \%$ of ecigarettes and 37\% THPs values. In Japan, where both PRRP products are established, a nationwide population survey estimated the patterns of use of tobacco product use in 
TABLE 2 | Two-product model data sources.

\begin{tabular}{|c|c|}
\hline Demographics & Data sources \\
\hline Population size & $\begin{array}{l}\text { EUROSTAT (21) } \\
\text { Population (t demo_pop) } \\
\text { https://ec.europa.eu/eurostat/web/main/data/database }\end{array}$ \\
\hline $\begin{array}{l}\text { Projected birth } \\
\text { rate }\end{array}$ & $\begin{array}{l}\text { ISTAT (22) (STATBASE) } \\
\text { Demographic Projections (2018-2065) } \\
\text { https://www.istat.it/en/analysis-and-products/databases/ } \\
\text { statbase }\end{array}$ \\
\hline Mortality rates & $\begin{array}{l}\text { ISTAT (23) (STATBASE) } \\
\text { Life Tables (2011-2012) } \\
\text { https://www.istat.it/en/analysis-and-products/databases/ } \\
\text { statbase }\end{array}$ \\
\hline Life expectancy & $\begin{array}{l}\text { ISTAT (23) (STATBASE) } \\
\text { Life Tables (2011-2012) } \\
\text { https://www.istat.it/en/analysis-and-products/databases/ } \\
\text { statbase }\end{array}$ \\
\hline $\begin{array}{l}\text { Projected total } \\
\text { net migration }\end{array}$ & $\begin{array}{l}\text { ISTAT (22) (STATBASE) } \\
\text { Demographic Projections (2018-2065) } \\
\text { https://www.istat.it/en/analysis-and-products/databases/ } \\
\text { statbase }\end{array}$ \\
\hline $\begin{array}{l}\text { Net migration } \\
\text { age distribution }\end{array}$ & $\begin{array}{l}\text { EUROSTAT (24) } \\
\text { Assumption for Net Migration (proj_19nanmig) } \\
\text { https://ec.europa.eu/eurostat/web/population-demography- } \\
\text { migration-projections/population-projections-data }\end{array}$ \\
\hline \multicolumn{2}{|c|}{ Smoking prevalence } \\
\hline $\begin{array}{l}\text { Smoking } \\
\text { prevalence }\end{array}$ & $\begin{array}{l}\text { ISTAT (25) (STATBASE) } \\
\text { Health Statistics > Life styles and Risk Factors >Smoking Habit } \\
\text { https://www.istat.it/en/analysis-and-products/databases/ } \\
\text { statbase }\end{array}$ \\
\hline $\begin{array}{l}\text { Quit time } \\
\text { distribution }\end{array}$ & $\begin{array}{l}\text { Estimated from: US DHHS (26) Population Assessment of } \\
\text { Tobacco and Health (PATH) Study [United States] https:// } \\
\text { www.icpsr.umich.edu/web/NAHDAP/studies/36498 }\end{array}$ \\
\hline \multicolumn{2}{|l|}{ Transitions } \\
\hline $\begin{array}{l}\text { Smoking } \\
\text { initiation }\end{array}$ & $\begin{array}{l}\text { ISTAT (25) (STATBASE) } \\
\text { Health Statistics > Life styles and Risk Factors >Smoking Habit } \\
\text { https://www.istat.it/en/analysis-and-products/databases/ } \\
\text { statbase }\end{array}$ \\
\hline $\begin{array}{l}\text { Smoking quit } \\
\text { probability }\end{array}$ & $\begin{array}{l}\text { ISTAT (25) (STATBASE) } \\
\text { Health Statistics > Life styles and Risk Factors >Smoking Habit } \\
\text { https://www.istat.it/en/analysis-and-products/databases/ } \\
\text { statbase }\end{array}$ \\
\hline $\begin{array}{l}\text { Smoking relapse } \\
\text { probability }\end{array}$ & $\begin{array}{l}\text { Hawkins et al. (27) } \\
\text { Long-term smoking relapse: a study using the British } \\
\text { household panel survey. }\end{array}$ \\
\hline $\begin{array}{l}\text { E-cigarette } \\
\text { transitions }\end{array}$ & $\begin{array}{l}\text { Brouwer et al. (19) } \\
\text { Transitions between cigarette, ENDS and dual use in adults in } \\
\text { the PATH study. }\end{array}$ \\
\hline THP transitions & $\begin{array}{l}\text { Adamson et al. (28); Camacho et al. (20) } \\
\text { Modeling the Population Health Impacts of Heated Tobacco } \\
\text { Products in Japan. }\end{array}$ \\
\hline \multicolumn{2}{|l|}{ Product risks } \\
\hline $\begin{array}{l}\text { Relative risk of } \\
\text { smoking }\end{array}$ & $\begin{array}{l}\text { US DHHS (29) National Center for Chronic Disease Prevention } \\
\text { and Health Promotion (US) } \\
\text { The Health Consequences of Smoking--50 Years of Progress: } \\
\text { A Report of the Surgeon General } \\
\text { https://www.cdc.gov/tobacco/data_statistics/sgr/50th- } \\
\text { anniversary/index.htm }\end{array}$ \\
\hline $\begin{array}{l}\text { Decay in former } \\
\text { smoker risk }\end{array}$ & $\begin{array}{l}\text { Lee et al. (30). } \\
\text { Using the Negative Exponential Model to Describe Changes in } \\
\text { Risk of Smoking-Related Diseases following Changes in } \\
\text { Exposure to Tobacco. }\end{array}$ \\
\hline
\end{tabular}

(Continued)
TABLE 2 | Continued

\begin{tabular}{|c|c|}
\hline Demographics & Data sources \\
\hline $\begin{array}{l}\text { E-cigarette risk } \\
\text { ratio compared } \\
\text { to smoking }\end{array}$ & $\begin{array}{l}\text { McNeill et al. (31) Public Health England. } \\
\text { Evidence review of e-cigarettes and heated tobacco products } \\
\text { https://assets.publishing.service.gov.uk/government/uploads/ } \\
\text { system/uploads/attachment_data/file/684963/Evidence_ } \\
\text { review_of_e-cigarettes_and_heated_tobacco_products_2018. } \\
\text { pdf }\end{array}$ \\
\hline $\begin{array}{l}\text { THP risk ratio } \\
\text { compared to } \\
\text { smoking }\end{array}$ & $\begin{array}{l}\text { UK Government Select Committees > Science and } \\
\text { Technology } \\
\text { Reducing Harm - Heat-not-burn tobacco products (para 28) } \\
\text { (2018) } \\
\text { https://publications.parliament.uk/pa/cm201719/cmselect/ } \\
\text { cmsctech/505/50505.htm\#_idTextAnchor007 }\end{array}$ \\
\hline
\end{tabular}

adolescents (32). A simple ratio of ever use of either PRRP product is used to generate the 63:37 ratio. In addition, the risk ratio of the pseudo PRRP is set to the weighted ratio of the e-cigarette and THP risk, 6.85\% that of combustible cigarettes.

6. Smoking and E-Cigarettes Transitions (Sensitivity)

E-cigarettes are added as the only alternative product to cigarettes in 2010 with transition probabilities selected from within the 95\% confidence interval range using random selection routine to generate one thousand sensitivity runs.

7. Smoking and THP (Transitions Sensitivity)

THPs are added as the only alternative product to cigarettes in 2014 with transition probabilities selected from within the $95 \%$ confidence interval range using random selection routine to generate one thousand sensitivity runs.

Additionally, we repeated scenarios 1-5 with a new "what if" assumption:

a) Smoking initiation rates decline at $3 \%$ per year from 2020 onwards.

\section{RESULTS}

\section{Three-Product Model}

For illustrative purposes only, when comparing life-years lost in Scenario 1 (cigarettes only) and Scenario 2 (two products available, cigarettes and e-cigarettes), the model indicates that life years lost due to smoking could be reduced by 17.6 million by 2100 (Table 3).

Compared with Scenario 3, Scenario 3 (all three products are available) is estimated to lead to an additional reduction of $13.4 \mathrm{~m}$ life-years lost by 2100 . Thus, with THPs and e-cigarettes available, the total reduction of life-years lost would be 31 million. In other words, introducing both products would have a synergistic effect that increases the potential overall benefit. Table 3 also shows projections of what would happen if e-cigarette users were to initiate into THP use instead of vaping at different rates, i.e., initiating e-cigarettes with a risk ratio of $10 \%$ rather than one with $5 \%$.

\section{Two-Product Models}

In Table 4, the smoking initiation and cessation probabilities are static over the projection period. The projected smoking 
TABLE 3 | Life-years saved by 2100 when comparing scenario 2 (cigarettes and e-cigarettes available) and scenario 3 (all three products) to scenario 1 (only cigarettes available).

\begin{tabular}{|c|c|c|c|c|c|c|c|c|c|c|}
\hline $\begin{array}{l}\text { Scenarios } \\
\text { (reduction in million life-year lost) }\end{array}$ & 2010 & 2020 & 2030 & 2040 & 2050 & 2060 & 2070 & 2080 & 2090 & 2100 \\
\hline 2. Only e-cigarettes & 0.0 & 0.07 & 0.57 & 1.70 & 3.36 & 5.33 & 7.51 & 10.15 & 13.79 & 17.61 \\
\hline 3. Both PRRPs & 0.0 & 0.07 & 0.72 & 2.59 & 5.65 & 9.46 & 13.71 & 18.63 & 24.82 & 31.03 \\
\hline $3.120 \%$ vapers initiate THP & 0.0 & 0.07 & 0.72 & 2.59 & 5.65 & 9.47 & 13.70 & 18.62 & 24.79 & 30.99 \\
\hline $3.240 \%$ vapers initiate THP & 0.0 & 0.07 & 0.72 & 2.59 & 5.65 & 9.47 & 13.69 & 18.60 & 24.74 & 30.94 \\
\hline $3.380 \%$ vapers initiate THP & 0.0 & 0.07 & 0.72 & 2.59 & 5.65 & 9.47 & 13.67 & 18.50 & 24.60 & 30.77 \\
\hline 3.4 All vapers initiate THP & 0.0 & 0.07 & 0.72 & 2.59 & 5.65 & 9.47 & 13.63 & 18.38 & 24.42 & 30.56 \\
\hline
\end{tabular}

TABLE 4 | Projected prevalence and reduction of life years lost for scenarios 1-5.

\begin{tabular}{|c|c|c|c|c|c|c|c|c|c|c|}
\hline Scenarios 1-5 & 2010 & 2020 & 2030 & 2040 & 2050 & 2060 & 2070 & 2080 & 2090 & 2100 \\
\hline \multicolumn{11}{|l|}{ Smoking prevalence (\%) } \\
\hline Smoking only & 19.7 & 16.6 & 14.3 & 12.7 & 11.6 & 11.2 & 11.3 & 11.2 & 11.2 & 11.3 \\
\hline Smoking + E-cigarettes & 19.7 & 15.3 & 12.7 & 10.9 & 9.8 & 9.5 & 9.5 & 9.5 & 9.5 & 9.6 \\
\hline Smoking + THPs & 19.7 & 13.7 & 7.3 & 5.4 & 4.7 & 4.6 & 4.6 & 4.6 & 4.6 & 4.7 \\
\hline Smoking + 50\% E-Cig 50\% THPs & 19.7 & 14.5 & 11.1 & 9.3 & 8.4 & 8.1 & 8.1 & 8.1 & 8.1 & 8.2 \\
\hline Smoking + 63\% E-Cig 37\% THPs & 19.7 & 14.8 & 11.7 & 9.9 & 8.9 & 8.6 & 8.6 & 8.6 & 8.6 & 8.7 \\
\hline \multicolumn{11}{|l|}{ PRRP prevalence (\%) } \\
\hline Smoking only & 0.0 & 0.0 & 0.0 & 0.0 & 0.0 & 0.0 & 0.0 & 0.0 & 0.0 & 0.0 \\
\hline Smoking + E-cigarettes & 0.0 & 2.7 & 2.2 & 1.8 & 1.6 & 1.6 & 1.6 & 1.6 & 1.6 & 1.7 \\
\hline Smoking + THPs & 0.0 & 6.7 & 9.6 & 8.9 & 7.8 & 7.3 & 7.2 & 7.1 & 7.1 & 7.1 \\
\hline Smoking + 50\% E-Cig 50\% THPs & 0.0 & 4.6 & 4.0 & 3.1 & 2.6 & 2.5 & 2.5 & 2.5 & 2.5 & 2.6 \\
\hline Smoking + 63\% E-Cig 37\% THPs & 0.0 & 4.0 & 3.3 & 2.6 & 2.2 & 2.2 & 2.2 & 2.2 & 2.2 & 2.2 \\
\hline \multicolumn{11}{|c|}{ Reduction of life years lost compared to smoking only scenario (million person years) } \\
\hline Smoking only & 0.0 & 0.0 & 0.0 & 0.0 & 0.0 & 0.0 & 0.0 & 0.0 & 0.0 & 0.0 \\
\hline Smoking + E-cigarettes & 0.0 & 0.0 & 0.2 & 0.6 & 1.2 & 1.7 & 2.1 & 2.5 & 2.7 & 3.0 \\
\hline Smoking + THPs & 0.0 & 0.0 & 0.7 & 2.3 & 4.4 & 6.2 & 7.6 & 8.8 & 9.8 & 10.7 \\
\hline Smoking + 50\% E-Cig 50\% THPs & 0.0 & 0.0 & 0.4 & 1.1 & 2.1 & 2.9 & 3.7 & 4.3 & 4.8 & 5.2 \\
\hline Smoking + 63\% E-Cig 37\% THPs & 0.0 & 0.0 & 0.3 & 0.9 & 1.7 & 2.4 & 3.0 & 3.5 & 4.0 & 4.3 \\
\hline
\end{tabular}

prevalence in people aged 14 and over reduces from 19.7\% (2010) to $11.3 \%(2100)$ a reduction of $8.4 \%$. The fall in prevalence occurs mostly in the period up to $2050(8.1 \%)$.

Based on Japan transition data, the THP scenario projects the greatest drop in smoking prevalence, with $4.7 \%$ smoking prevalence by the end of the projection period. In comparison, the inclusion of e-cigarettes, based on USA transitions, only reduces smoking prevalence down to $9.6 \%$. The scenarios with a mix of e-cigarettes and THPs project slightly lower smoking prevalence at $8.2 \%$ (50/50 $\mathrm{mix}$ ) and $8.7 \%$ (63/37 mix).

E-cigarette prevalence, when introduced alongside smoking, peaks at $2.7 \%$ in 2020 and then declines to a plateau of $1.6 \%$ before starting to rise again slightly in 2100 . THP prevalence, when introduced alongside smoking, peaks at $9.6 \%$ in 2030 and then declines to a plateau of $7.1 \%$. The scenarios using a mix of both e-cigarettes and THPs are above those with e-cigarettes only and below those with THPs only.

Comparing the reduction of life years lost across alternative scenarios against those projected for the smoking only scenario, the largest health gain is $10.7 \mathrm{~m}$ for the THP only scenario.
This is over three times the number for the E-Cigarette only scenario, which projects a reduction of $3.0 \mathrm{~m}$ live years lost. Taking a similar approach as per the three-product model, if all these e-cigarette users were using THP (with risk ratio of $10 \%$ ) the new projection for life years lost would be $2.9 \mathrm{~m}$.

To this point all projections were based on fixed smoking initiation probabilities. In Table 5 the same scenarios assessed before are drawn with $3 \%$ annual reduction in the smoking initiation. These alternative scenarios provide a more realistic representation in many markets with smoking declines independently of any PRRP introduced to the market. Under these conditions, the Smoking Only scenario projected that smoking prevalence in people aged 14 and over reduces from $19.7 \%$ (2010) to $2.9 \%$ (2100), a reduction of 16.8 percentage points. The fall in smoking prevalence occurs more rapidly in earlier projection years but, a year on year drop, is projected across all years.

After introduction of THPs, the scenario projects the greatest drop in smoking prevalence, with $0.8 \%$ smoking prevalence by 
TABLE 5 | Projected prevalence and reduction of life years lost for scenarios 1a-5a.

\begin{tabular}{|c|c|c|c|c|c|c|c|c|c|c|}
\hline Scenarios $1 a-5 a$ & 2010 & 2020 & 2030 & 2040 & 2050 & 2060 & 2070 & 2080 & 2090 & 2100 \\
\hline \multicolumn{11}{|l|}{ Smoking prevalence (\%) } \\
\hline Smoking only & 19.7 & 16.6 & 14.0 & 11.6 & 9.4 & 7.7 & 6.3 & 5.0 & 3.8 & 2.9 \\
\hline Smoking + E-cigarettes only & 19.7 & 15.3 & 12.4 & 9.9 & 7.9 & 6.4 & 5.1 & 3.9 & 2.7 & 1.7 \\
\hline Smoking + THPs Only & 19.7 & 13.7 & 7.1 & 4.5 & 3.3 & 2.5 & 2.0 & 1.5 & 1.1 & 0.8 \\
\hline Smoking + 50\% E-Cig 50\% THPs & 19.7 & 14.5 & 10.8 & 8.4 & 6.6 & 5.3 & 4.3 & 3.4 & 2.5 & 1.8 \\
\hline Smoking + 63\% E-Cig 37\% THPs & 19.7 & 14.8 & 11.4 & 8.9 & 7.1 & 5.7 & 4.6 & 3.6 & 2.7 & 1.9 \\
\hline \multicolumn{11}{|l|}{ PRRP prevalence (\%) } \\
\hline Smoking only & 0.0 & 0.0 & 0.0 & 0.0 & 0.0 & 0.0 & 0.0 & 0.0 & 0.0 & 0.0 \\
\hline Smoking + E-cigarettes only & 0.0 & 2.7 & 2.2 & 1.7 & 1.5 & 1.3 & 1.2 & 1.1 & 1.0 & 1.0 \\
\hline Smoking + THPs only & 0.0 & 6.7 & 9.6 & 8.5 & 6.9 & 5.6 & 4.7 & 3.9 & 3.3 & 2.8 \\
\hline Smoking + 50\% E-Cig 50\% THPs & 0.0 & 4.6 & 4.0 & 2.9 & 2.2 & 1.9 & 1.7 & 1.5 & 1.3 & 1.2 \\
\hline Smoking + 63\% E-Cig 37\% THPs & 0.0 & 4.0 & 3.3 & 2.4 & 1.9 & 1.7 & 1.5 & 1.3 & 1.2 & 1.1 \\
\hline \multicolumn{11}{|c|}{ Life years saved compared to smoking only scenario (million person years) } \\
\hline Smoking only & 0.0 & 0.0 & 0.0 & 0.0 & 0.0 & 0.0 & 0.0 & 0.0 & 0.0 & 0.0 \\
\hline Smoking + E-cigarettes only & 0.0 & 0.0 & 0.2 & 0.6 & 1.2 & 1.7 & 2.1 & 2.4 & 2.5 & 2.6 \\
\hline Smoking + THPs only & 0.0 & 0.0 & 0.7 & 2.3 & 4.4 & 6.1 & 7.5 & 8.5 & 9.3 & 9.9 \\
\hline Smoking + 50\% E-Cig 50\% THPs & 0.0 & 0.0 & 0.4 & 1.1 & 2.1 & 2.9 & 3.6 & 4.1 & 4.5 & 4.7 \\
\hline Smoking + 63\% E-Cig 37\% THPs & 0.0 & 0.0 & 0.3 & 0.9 & 1.7 & 2.4 & 3.0 & 3.4 & 3.7 & 3.9 \\
\hline
\end{tabular}

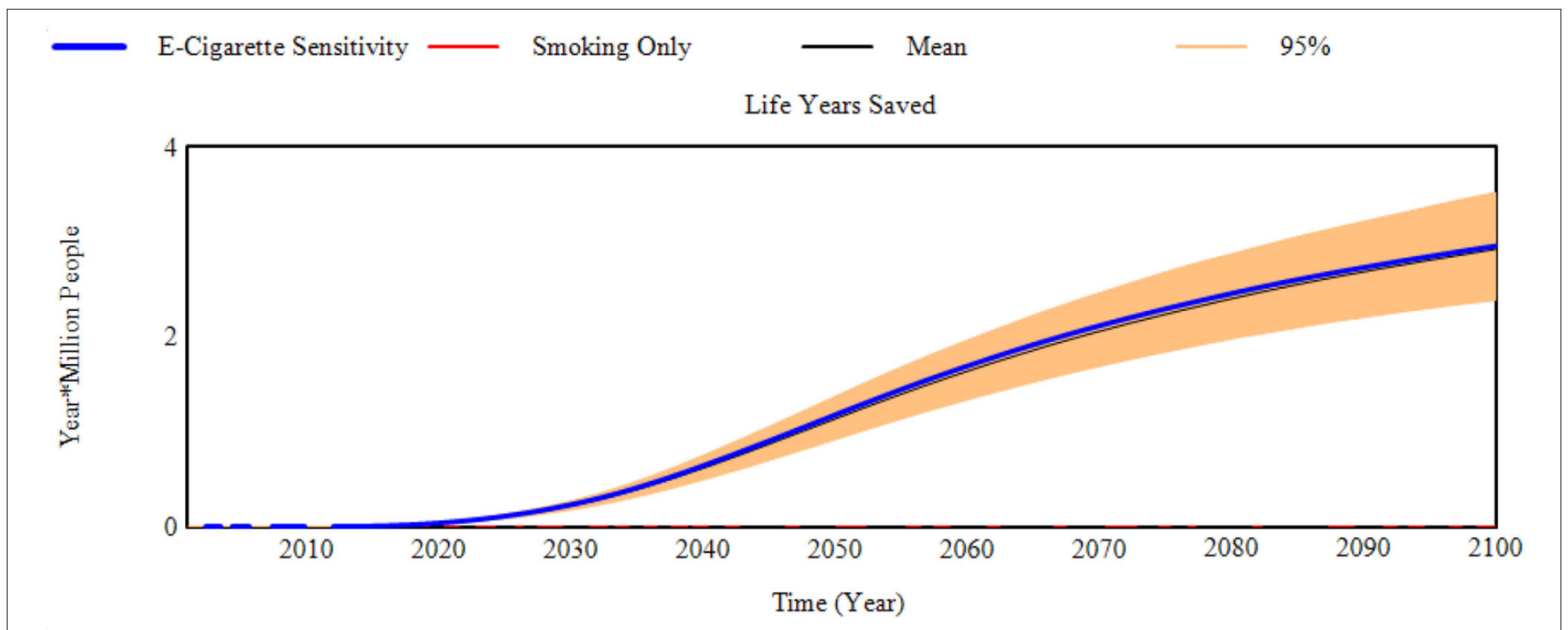

FIGURE 3 | Reduction in life years lost compared to the smoking only scenario (Life years saved) for the E-Cigarette scenario sensitivity to transition probabilities.

the end of the projection period. In comparison, the inclusion of e-cigarettes reduces smoking prevalence down to $1.7 \%$. The scenarios with a mix of e-cigarettes and THPs project smoking prevalence's of 1.8\% (50/50 mix) and 1.9\% (63/37 mix).

E-cigarette prevalence, when introduced alongside smoking, peaks at $2.7 \%$ in 2020 and then declines to a plateau of $1.0 \%$. This value is lower than from the scenario with static initiation probabilities as expected, as there will be fewer smokers to transition to e-cigarettes. THP prevalence, when introduced alongside smoking, peaks at $9.6 \%$ in 2030 and then declines to
$2.8 \%$ by 2100 . The projections from scenarios using a mix of both e-cigarettes and THPs are above those for e-cigarettes only and below those for THPs only.

Comparing to the smoking only scenario, the largest reduction in life years lost is $9.9 \mathrm{~m}$ for the THP only scenario, down from $10.7 \mathrm{~m}$ previously projected when the $3 \%$ annual decline was not applied to the initiation rate. However, comparatively, reductions in projections are still over three times the life years lost projected using the E-Cigarette only scenario, which projects a reduction of $2.6 \mathrm{~m}$ in life years lost. 


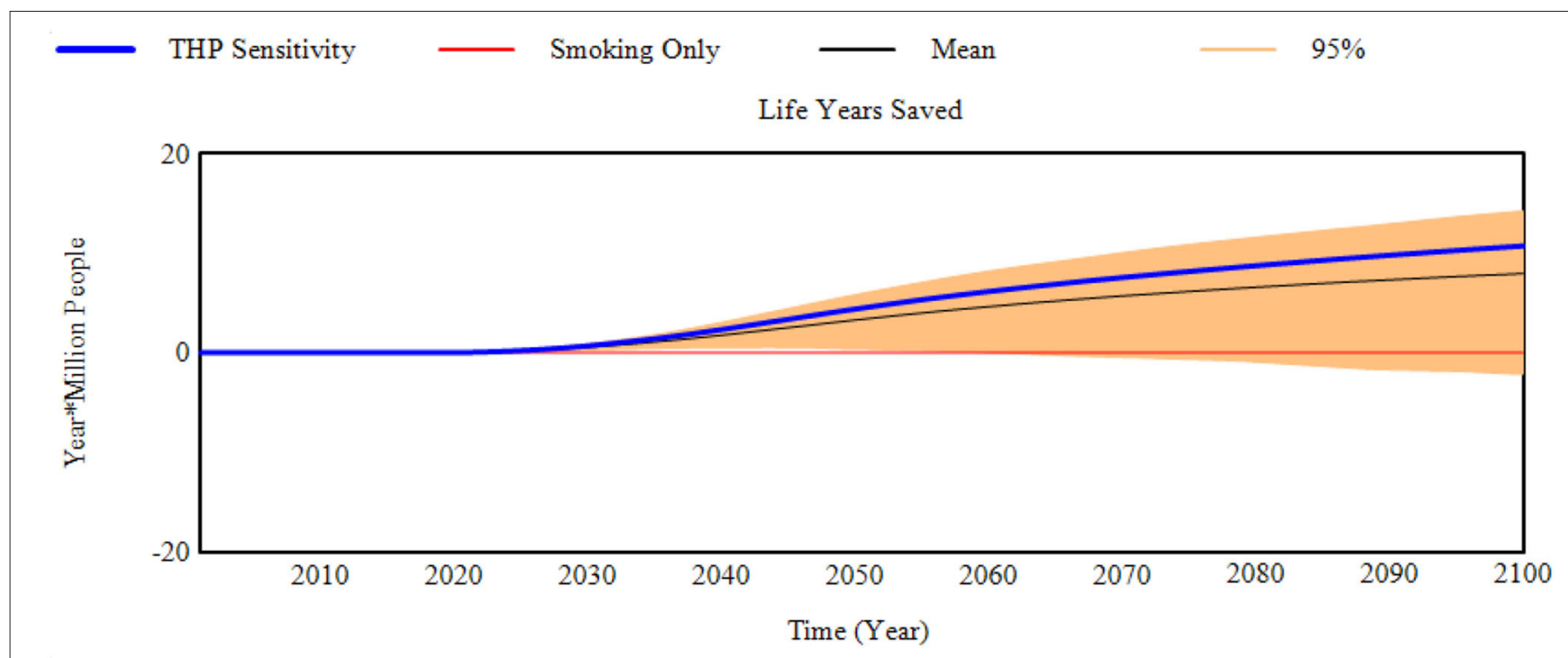

FIGURE 4 | Reduction in life years lost compared to the smoking only scenario (Life years saved) for the THP scenario sensitivity to transition probabilities.

\section{Sensitivity Assessment}

Sensitivity assessments present 1,000 projections drawn using the transitions' 95\% confidence intervals from either the E-Cigarette scenario based on USA data (19) and THP scenario based on Japan data (20). Reductions in life years lost (as life years saved for brevity) for the E-Cigarette and THP scenarios are displayed in Figures 3, 4. Additional graphs reporting other aspects of the sensitivity assessment can be found in Supplementary File 3.

The model projections were not overly sensitivity to randomly selecting combinations of e-cigarette transition probabilities from within their 95\% confidence inter range (Table 6). By comparison, the model projections were more sensitive to the random selection of THP transition probabilities from within their confidence intervals. This is most prominent in the projection of life years saved. Although the mean and median values ( 8.0 and $8.7 \mathrm{~m}$, respectively) were positive in terms of reducing life years lost compared to a smoking only scenario, certain randomly selected THP transition probabilities generated greater life years lost when compared to the smoking only scenario. Approximately 5\% of the 1,000 sensitivity runs suggest an increase in life years lost (Table 7), with the maximum of life years lost across all 1,000 scenarios at $5.8 \mathrm{~m}$ of additional life years that could be lost.

It is worth noticing that some of the THP transitions in Japan study have wide 95\% confidence intervals (Supplementary File 2 and Supplementary Table 9), particularly from the transitions from THP Users to Dual Use. The mean probability is 3.0\%, but the $95 \%$ confidence interval on this estimate ranges from 0.0 to $20.5 \%$. These wide confidence intervals have significant leverage on the sensitivity results.

\section{DISCUSSION}

The use of mathematical models has been suggested to assess the potential population health effects of launching new
TABLE 6 | Summary sensitivity results across all 1,000 projections for the E-cigarette and THP scenarios.

\begin{tabular}{lllll}
\hline Sensitivity results Min Max Mean Median $\begin{array}{l}\text { Standard } \\
\text { deviation }\end{array}$
\end{tabular}

\section{E-cigarette transition sensitivity}

$\begin{array}{llllll}\text { Smoking prevalence (\%) } & 9.1 & 10.1 & 9.6 & 9.6 & 0.2\end{array}$

$\begin{array}{llllll}\text { PRRP prevalence (\%) } & 1.4 & 1.8 & 1.5 & 1.5 & 0.1\end{array}$

$\begin{array}{llllll}\text { Life years saved }(\mathrm{M}) & 2.0 & 3.9 & 2.9 & 2.9 & 0.3\end{array}$

THP transition sensitivity

$\begin{array}{llllll}\text { Smoking prevalence (\%) } & 2.9 & 11.2 & 5.5 & 5.4 & 1.3\end{array}$

$\begin{array}{llllll}\text { PRRP prevalence (\%) } & 2.5 & 21.0 & 6.5 & 5.7 & 2.8\end{array}$

$\begin{array}{llllll}\text { Life years saved }(\mathrm{M}) & -5.8 & 15.7 & 8.0 & 8.7 & 4.2\end{array}$

TABLE 7 | Sensitivity percentiles for all 1,000 projections for the E-cigarette and THP scenarios.

\begin{tabular}{lccccc}
\hline Percentiles & $\mathbf{5 \%}$ & $\mathbf{1 0 \%}$ & $\mathbf{1 5 \%}$ & $\mathbf{2 0 \%}$ & $\mathbf{2 5 \%}$ \\
\hline $\begin{array}{l}\text { E-cigarette transition sensitivity } \\
\text { Smoking prevalence (\%) }\end{array}$ & 9.3 & 9.4 & 9.4 & 9.5 & 9.5 \\
PRRP prevalence (\%) & 1.4 & 1.4 & 1.5 & 1.5 & 1.5 \\
Life years saved (M) & 2.4 & 2.5 & 2.6 & 2.7 & 2.7 \\
THP transition sensitivity & & & & & \\
Smoking prevalence (\%) & 3.7 & 4.0 & 4.2 & 4.4 & 4.6 \\
PRRP prevalence (\%) & 3.5 & 3.7 & 4.0 & 4.2 & 4.4 \\
Life years saved (M) & -0.4 & 2.0 & 3.5 & 4.8 & 5.8 \\
\hline
\end{tabular}

nicotine products (2). Numerous models have been developed with this purpose (3). However, to our knowledge, all these models are two-product models and with increasing market complexity with competing PRRPs like e-cigarettes and THPs, two-product models may not be able to represent population dynamics appropriately. 
We have developed a three-product model with a structure considering interactions between all three products and allowing for 27 nicotine product use statuses. Our example illustrates how a three-product model is able to draw projections accounting for potential synergies between products that enhance harm reduction character of PRRPs. This aspect is lost in two-product models, however if the aim of the modeling assessment is to investigate the potential for a new product to introduce harm compared to a scenario where another PRRP already exists, separate models for the current and prospective PRRPs could be informative in relation to whether the prospective PRRP is likely to introduce benefit or burden at the population level.

We used the Italian population to assess e-cigarettes and THPs potential for harm reduction separately and considering that ecigarettes were introduced in Italy earlier than THPs. Given that Italian estimates on transitions to and from these PRRPs are not available, estimates calculated based on USA behaviors were used for the E-Cigarette scenario and for the THP scenario these were Japanese estimates.

To aid interpretability, it is essential to clarify that none these models forecast future tobacco product prevalence nor associated mortality rates. They generate projections based on data currently available and the underlying assumption that currently observed behavior will continue. Evaluation of whether models suggest mainly positive or negative effects are informative, especially when performing sensitivity testing, as well as the magnitude of changes between different scenarios. Sensitivity testing of model input data helps to identify key data, assisting the design of future surveys to gather that information.

Limitations on data availability, especially on transitions between two differing types of PRRPs, precluded any detailed projections using the three-product model. Using the twoproduct model, our projections from both models suggested beneficial effects from launching either product, the THPscenario suggested the largest point estimate in reductions of life-years lost while with higher uncertainty in outcomes. A $5 \%$ of projections in the sensitivity testing of the THP scenario pointed to additional life years lost, this was driven by wide confidence intervals for some transition estimates.

The fact that the THP scenario suggest three times greater effects reducing life years lost than the E-Cigarette model only can be surprising to many given that THPs have a higher risk ratio than e-cigarettes. This effect is due to the different dynamics observed between the Japan and USA populations. One of the judgements to be assessed on all PRRPs is the balance between moving existing smokers to a less harmful product against introducing a product with some risk to people that may never have smoked and eventually leading them to smoking, known as the gateway effect. In our scenarios, the THP scenario performed better than the E-Cigarette scenario because THP initiation by never smokers in Japan is a quarter of the initiation probability of e-cigarettes in the USA and THPs in Japan have double the transition probability of shifting existing smokers to the PRRP than e-cigarettes in the USA. A beneficial effect persists despite of overall greater nicotine prevalence in the THP scenario and even with a higher relative risk ratio than e-cigarettes.
Independent scenarios do not provide much information about a potential combined effect from using both products. In order to mitigate this problem, we suggest creating combined or hybrid two-product scenarios. These combined scenarios could be designed using weights based on expected prevalence ratio for the two PRRPs placing each transition point estimate between the two estimates for the independent PRRP transitions, as well as using their confidence intervals for sensitivity testing. In our examples we used 50:50 and 63:37 ratios and when rates are considered constant over time, projections from these scenarios lay between the E-Cigarette and THP scenarios. However, this may not always be case with the non-linear relationships within system dynamic models. This effect can be observed for the scenarios with $3 \%$ annual reduction in initiation rates, where results from these scenarios suggest that the combination of different tobacco transitions could lead to a smoking prevalence outcome outside the range of solely ecigarettes or solely THPs. For most of the projection period the combined scenario projections fall between the two sole product scenarios prevalence, but post-2090 both combined scenarios exceeded the smoking prevalence of the E-Cigarette or THP scenarios.

In Japan, nicotine containing e-cigarettes are banned and the new generation of THPs was granted only relatively recently a marketing authorization in the USA. Perhaps the same behaviors would have been observed in Japan if e-cigarettes were available instead THPs. Therefore, we do not know whether the alternative product would have similar transitions or not if both products coexisted in the same market under the same cultural and regulatory conditions. Thus, our results can only be interpreted as possible projections for the Italian population if they were to behave as the Japanese are using THP products or USA population with e-cigarettes. Transitions cannot be regarded purely as a product effect, as cultural, social and regulatory aspects will play an important role on transitions.

In principle, the three-product model is thought to be best suited to model the tobacco use behavior of three coexisting products, especially to estimate potential synergistic effects that could be observed if the two PRRP products were to attract a different pool of smokers. However, a clear limitation of a three-product model is the type and amount of data required to appropriately inform the model, with the many transitions involving the two PRRPs not likely to be available. This will be even more problematic as a larger number of PRRPs are included in the assessment, as the number of transitions and nicotine use statuses will increase in a multiplicative manner. Alternatively, we have suggested using several two-product models, building combined scenarios to draw credible scenarios with the limitation of missing any synergistic effect.

Other general limitations of our modeling come from using transition data from different sources which leads to inconsistencies in product use definitions. Smoking data in ISTAT does not have specific time constraints for current or former smokers as they are only asked if they currently smoked or they smoked in the past. The definition of product use status for e-cigarettes are based on usage in the previous 30 days while the e-cigarette transition probabilities are estimated from a Markov multistate transition model based on data approximately 
at 1-year intervals (19). The THP transition probabilities (20) are also based on 1-year intervals with product status definitions according to use in the last year. For e-cigarette initiation, this could mean that short-term experimental use of an ecigarette maybe overlooked. The authors judge that any health impact from a short-term, less than a year, e-cigarette use would be minimal.

In conclusion, we have developed a three-product model able to evaluate the population health effects of three coexisting tobacco products and showed that different implementations of two-product models can be informative when evaluating three products. In our case study, both THPs and e-cigarettes in Italy would suggest significant reductions in life years lost if the Italian population were to behave like the Japanese population with THPs and USA population with e-cigarettes, with significantly more gains from the behaviors observed in the Japanese population.

\section{LIMITATIONS}

The current model only simulates three co-existing tobaccorelated products, cigarettes, THPs and e-cigarettes. However, in future markets there are likely to be more alternatives to cigarette smoking, such as oral tobacco free nicotine pouches and snus. At present, the model characterizes the Italian population by age and gender only, but studies have shown ethnicity, social economic status, and education level to be important factors influencing smoking prevalence. The model assessed the impact on population health in Italy in terms of overall mortality rates and smoking-related mortality. We were required to make certain assumptions when constructing the model, for example the lack of available data, especially on transitions between two differing types of PRRPs, precluded any detailed projections using the three-product model. Additionally, average consumption rates were assumed throughout the model, but it could be argued that dual users are likely to consume lower

\section{REFERENCES}

1. Institute of Medicine (IoM). Clearing the Smoke: Assessing the Science Base for Tobacco Harm Reduction. Washington, DC: The National Academies Press (2001).

2. Modified Risk Tobacco Product Applications (MRTPA). Draft Guidance for Industry. US Food and Drug Administration. Draft guidance 2012 (2012). Available online at: https://www.fda.gov/regulatory-information/search-fdaguidance-documents/modified-risk-tobacco-product-applications (accessed March 9, 2021).

3. Lee PN, Abrams D, Bachand A, Baker J, Black R, Camacho R, et al. Estimating the population health impact of recently introduced modified risk tobacco products: a comparison of different approaches. Nicotine Tob Res. (2021) 23:426-37. doi: 10.1093/ntr/ntaa102

4. Bachand AM, Sulsky SI, Curtin GM. Assessing the likelihood and magnitude of a population health benefit following the market introduction of a modified-risk tobacco product: enhancements to the dynamic population modeler, DPM(+1). Risk Anal. (2018) 38:151-62. doi: 10.1111/risa.12819

5. Djurdjevic S, Lee PN, Weitkunat R, Sponsiello-Wang Z, Ludicke F, Baker J. Modeling the population health impact of introducing a modified numbers of cigarettes than they would if they did not also use THPs or e-cigarettes. Relative risks were not linked to duration of smoking, so it assumes similar smoking durations within age categories. However, a clear limitation of a three-product model is the type and amount of data required to appropriately inform the model, with the many transitions involving the two PRRPs not likely to be available. Other general limitations of our modeling come from using transition data from different sources which leads to inconsistencies in product use definitions.

\section{DATA AVAILABILITY STATEMENT}

The original contributions presented in the study are included in the article/Supplementary Material, further inquiries can be directed to the corresponding author.

\section{AUTHOR CONTRIBUTIONS}

OC: conceptualization-equal, investigation-equal, methodologyequal, project administration-lead, supervision-lead, and writing-original draft-lead. $\mathrm{AH}$ : conceptualization-equal, data curation-equal, formal analysis-lead, methodologyequal, software-lead, and writing-review and editing-equal. SF: conceptualization-supporting, data curation-equal, investigation-supporting, project administrationsupporting, and writing-review and editing-equal. AW: resources-supporting, writing-review and editing-equal. JM: conceptualization-equal and funding acquisition-lead. All authors contributed to the article and approved the submitted version.

\section{SUPPLEMENTARY MATERIAL}

The Supplementary Material for this article can be found online at: https://www.frontiersin.org/articles/10.3389/fpubh. 2021.700473/full\#supplementary-material risk tobacco product into the U.S. Market. Healthcare. (2018) 16:47. doi: 10.3390/healthcare6020047

6. Levy DT, Borland R, Villanti AC, Niaura R, Yuan Z, Zhang Y, et al. The application of a decision-theoretic model to estimate the public health impact of vaporized nicotine product initiation in the United States. Nicotine Tob Res. (2017) 19:149-59. doi: 10.1093/ntr/ntw158

7. Hori A, Tabuchi T, Kunugita N. Rapid increase in heated tobacco product (HTP) use from 2015 to 2019: from the Japan 'Society and New Tobacco' Internet Survey (JASTIS). Tob Control. (2020) 30:474-5. doi: 10.1136/tobaccocontrol-2020-055652

8. Forster M, Fiebelkorn S, Yuteri C, Mariner D, Liu C, Wright C, et al. Assessment of novel tobacco heating product THP1.0 Part 3: comprehensive chemical characterisation of harmful and potentially harmful aerosol emissions. Regul Toxicol Pharmacol. (2017) 86:265-78. doi: 10.1016/j.yrtph.2017.10.006

9. Gale NJ, McEwan M, Eldridge AC, Fearon IM, Sherwood N, Bowen $\mathrm{E}$, et al. Changes in biomarkers of exposure on switching from a conventional cigarette to tobacco heating products: a randomized, controlled study in healthy Japanese subjects. Nicotine Tob Res. (2018) 21:1220-7. doi: $10.1093 /$ ntr/nty104 
10. Schaller JP, Keller D, Poget L, Pratte P, Kaelin E, McHugh G, et al. Evaluation of the tobacco heating system 2.2. Part 2: chemical composition, genotoxicity, cytotoxicity, and physical properties of the aerosol. Regul Toxicol Pharmacol. (2016) 81:S27-47. doi: 10.1016/j.yrtph.2016.10.001

11. Villarroel MA, Cha AE, Vahratian A. Electronic Cigarette Use Among U.S. Adults, 2018. NCHS Data Brief, no 365. Hyattsville, MD: National Center for Health Statistics (2020). Available online at: https://www.cdc.gov/nchs/ products/databriefs/db365.htm (accessed March 9, 2021).

12. Margham J, McAdam K, Forster M, Liu C, Wright C, Mariner D, et al. Chemical composition of aerosol from an E-cigarette: a quantitative comparison with cigarette Smoke. Chem Res Toxicol. (2016) 29:1662-78. doi: 10.1021/acs.chemrestox.6b00188

13. Chen J, Bullen C, Dirks K. A comparative health risk assessment of electronic cigarettes and conventional cigarettes. Int J Environ Res Public Health. (2017) 14:382. doi: 10.3390/ijerph14040382

14. Gallus S, Lugo A, Pacifici R, Pichini S, Colombo P, Garattini S, et al. E-cigarette awareness, use, and harm perceptions in Italy: a national representative survey. Nicotine Tob Res. (2014) 16:1541-8. doi: 10.1093/ntr/ntu124

15. Liu X, Lugo A, Davoli E, Gorini G, Pasifici R, Fernández E, et al. Electronic cigarettes in Italy: a tool for harm reduction or a gateway to smoking tobacco? Tob Control. (2020) 29:148-52. doi: 10.1136/tobaccocontrol-2018-054726

16. Gallus S, Lugo A, Colombo P, Pacifici R, La Vecchia C. Smoking prevalence in Italy 2011 and 2012, with a focus on hand-rolled cigarettes. Prev Med. (2013) 56:314-8. doi: 10.1016/j.ypmed.2013.02.009

17. Liu X, Lugo A, Spizzichino L, Tabuchi T, Gorini G, Gallus S. Heat-notburn tobacco products are getting hot in Italy. J Epidemiol. (2018) 28:274-5. doi: 10.2188/jea.JE20180040

18. Hill A, Camacho OM. A System Dynamics modelling approach to assess the impact of launching a new nicotine product on population health outcomes. Regul Toxicol Pharmacol. (2017) 86:265-78. doi: 10.1016/j.yrtph.2017.03.012

19. Brouwer A F, Jeon J, Hirschtick JL, Jimenez-Mendoza E, Mistry R, Bondarenko IV, et al. Transitions between cigarette, ENDS and dual use in adults in the PATH study (waves 1-4): multistate transition modelling accounting for complex survey design. Tob Control. (2020). doi: 10.1136/tobaccocontrol-2020-055967. [Epub ahead of print].

20. Camacho OM, Hill A, Fiebelkorn S, Jones JD, Prasad K, Proctor C, et al. Modelling the population health impacts of heated tobacco products in Japan. Tob Regul Sci. (2021) 7:221-23. doi: 10.18001/TRS.7.3.7

21. EUROSTAT. Population (t_demo_pop). Population Change - Demographic Balance and Crude Rates at National Level. Online Data Code: DEMO_GIND. Source of Data: Eurostat. Available online at: https://ec.europa.eu/eurostat/ web/main/data/database (accessed March 9, 2021).

22. ISTAT. Demographic Projections - Years 2018-2065, Demographic Indicators. STATBASE Population and Households $>$ Demographic Projections $>$ Demographic Projections (2018-2065)>Demographic indicators. Available online at: https://www.istat.it/en/analysis-and-products/databases/ statbase (accessed March 9, 2021).

23. ISTAT. Life Tables. Years 2011-2012. STATBASE Population and Households $>$ Mortality $>$ Life Tables. Available online at: https://www.istat.it/ en/analysis-and-products/databases/statbase (accessed March 9, 2021).

24. EUROSTAT. Assumptions for Net Migration by Age, Sex and Type of Projection (proj_19nanmig). Online data code: PROJ_19NANMIG. Source of data: Eurostat. Available online at: https:/ec.europa.eu/eurostat/web/ population-demography-migration-projections/population-projectionsdata (accessed March 9, 2021).

25. ISTAT. Smoking Habit. STATBASE Health Statistics $>$ Life styles and Risk Factors $>$ Smoking Habit. Available online at: https://www. istat.it/en/analysis-and-products/databases/statbase (accessed March 9, 2021).

26. PATHSTUDY United States Department of Health, and Human Services. National Institutes of Health. National Institute on Drug Abuse, and United States Department of Health and Human Services. Food and Drug Administration. Center for Tobacco Products. Population Assessment of Tobacco and Health (PATH) Study [United States] Public-Use Files. Interuniversity Consortium for Political and Social Research [distributor] (2020).

27. Hawkins J, Hollingworth W, Campbell R. Long-term smoking relapse: a study using the British household panel survey. Nicotine Tob Res. (2010) 12:1228-35. doi: 10.1093/ntr/ntq175

28. Adamson J, Kanitscheider C, Prasad K, Camacho OM, Beyerlein E, Bhagavan YK, et al. Results from a 2018 cross-sectional survey in Tokyo, Osaka and Sendai to assess tobacco and nicotine product usage after the introduction of heated tobacco products (HTPs) in Japan. Harm Reduct J. (2020) 17:32. doi: 10.1186/s12954-020-00374-3

29. National Center for Chronic Disease Prevention and Health Promotion (US) Office on Smoking and Health. The Health Consequences of Smoking--50 Years of Progress: A Report of the Surgeon General. Atlanta, GA: Centers for Disease Control and Prevention (U. S.) (2014).

30. Lee P, Hamlin J, Fry J, Forey B. Using the negative exponential model to describe changes in risk of smoking-related diseases following changes in exposure to tobacco. Adv Epidemiol. (2015) 2015:487876. doi: 10.1155/2015/487876

31. McNeill A, Brose LS, Calder R, Bauld L, Robson D. Evidence Review of e-Cigarettes and Heated Tobacco Products 2018. A report commissioned by Public Health England, 2018 Public Avaiulable online at: https://assets. publishing.service.gov.uk/government/uploads/system/uploads/attachment_ data/file/684963/Evidence_review_of_e-cigarettes_and_heated_tobacco_ products_2018.pdf (accessed March 9, 2021).

32. Kuwabara Y, Kinjo A, Fujii M, Imamoto A, Osaki Y, Jike M, et al. Heatnot-burn tobacco, electronic cigarettes, and combustible cigarette use among Japanese adolescents: a nationwide population survey 2017. BMC Public Health. (2020) 20:741. doi: 10.1186/s12889-020-08916-x

Conflict of Interest: OC, SF, AW, and JM are employees of British American Tobacco. This work was fully funded by British American Tobacco (Investments) Limited.

The remaining author declares that the research was conducted in the absence of any commercial or financial relationships that could be construed as a potential conflict of interest.

Publisher's Note: All claims expressed in this article are solely those of the authors and do not necessarily represent those of their affiliated organizations, or those of the publisher, the editors and the reviewers. Any product that may be evaluated in this article, or claim that may be made by its manufacturer, is not guaranteed or endorsed by the publisher.

Copyright (C) 2021 Camacho, Hill, Fiebelkorn, Williams and Murphy. This is an open-access article distributed under the terms of the Creative Commons Attribution License (CC BY). The use, distribution or reproduction in other forums is permitted, provided the original author(s) and the copyright owner(s) are credited and that the original publication in this journal is cited, in accordance with accepted academic practice. No use, distribution or reproduction is permitted which does not comply with these terms. 